\title{
A Discrete Wavelet transform based Protection Scheme for Three Phase Induction Motor
}

\author{
Musthak Ahmed Shaik, Sudheer Vinnakoti, Malligunta Kiran Kumar
}

\begin{abstract}
This paper has proposed an approachwhich detects the stator turn to turn faults and phase to ground faults in stator winding of three induction motor. This method proposes analysis of stator winding currents for both normal and fault conditions. High frequency universal model of three phase induction motor used for MATLAB simulation. By using the wavelet MRA technique, the approximate and detailed coefficients of the faulty voltage and current waveforms of the machine are generated under different fault conditions. From the approximate coefficients the type of the fault has been identified. Depending on the energies of the signal the fault diagnosis can be done. The proposed protection scheme is reliable and fast for various fault inception angles.
\end{abstract}

\section{Keywords : wavelet transform, induction motor, protection}

\section{INTRODUCTION}

Induction motor is a singly excited machine. These motors have two windings namely excitation winding and armature winding. Here the excitation winding is connected to supply. The armature winding is isolated. The armature winding carries currents due to electromagnetic induction and interacts with stator winding field and produces one directional torque. An asynchronous machine may be considered to be a transformer in the sense that the power is transferred from the stationary winding to the rotating winding by electromagnetic induction [8].Due to which, such a machine is often called the induction machine. In motors with ratings up to $100 \mathrm{kw}$, the squirrel cage is formed by casting aluminum (under pressure) in rotor core slots. According to Lenz's law we know that effect opposes its cause of production. The speed of the rotor will be reduced due to the deceleration produced by the interaction of rotor and stator fields. Due to abnormal conditions stator faults and rotor faults occur in an induction motor[1].

In Stator winding open faults, phase - ground faults and turn-turn faults occur. So many people proposed different methods for fault detection of induction motors. To analyse the induction motor under different conditions the models

Manuscript published on 30 September 2019

* Correspondence Author

Musthak Ahmed Shaik*, Research Scholar, Department of EEE, Koneru Lakshmaiah Education Foundation, Vaddeswaram, A.P, India.

Sudheer Vinnakoti, Department of EEE, Raghu Engineering College

(A), Dakamarri (V), Bheemunipatnam (M), A.P, India.

Malligunta Kiran Kumar, Department of EEE, Koneru Lakshmaiah Education Foundation, Vaddeswaram, A.P, India

(C) The Authors. Published by Blue Eyes Intelligence Engineering and Sciences Publication (BEIESP). This is an open access article under the CC-BY-NC-ND license http://creativecommons.org/licenses/by-nc-nd/4.0/ developed for phase to ground and turn to turn faults are very much useful.

Various mathematical transform techniques are useful for analysis of various non stationary signals. During fault conditions in an induction motor the current and voltage signals become non stationary. Fourier, STFT and wavelet transforms are more useful in obtaining better resolution. In this paper a wavelet base MRA scheme proposed to detect the faults in 3 phase induction motor.

\section{WAVELET ANALYSIS}

'Using mother wavelet suitable to the obtained signals plays vital role here. Dilation and scaling features of mother wavelet gives more emphasis for analysis of signals. Using wavelets signal is divided into two components with the help of high pass and low pass filters. The unique features of wavelet transforms provides more resolution of frequency data[2]. The wavelet is sum of so many waves with zero average value.

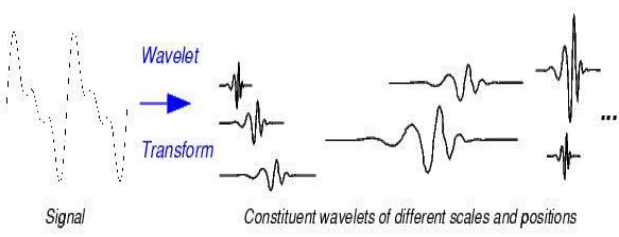

Fig 1. Demonstration of a Wave and a Wavelet.

Wavelet transforms based techniques have more diversified methods like discrete, continuous and packet transforms[3], these methods enables for more reliable method for fault diagnosis of 3 phase induction motor faults.

Here the phase currents in stator under normal and abnormal conditions were analyzed using wavelet based technique. The approximate and detailed coefficients used for the detection of turn to turn faults and phase to ground faults in an induction motor[4]. Here using MRA analysis with discrete wavelet transform, the stator winding currents were passed through high pass and low pass filters to obtain different coefficients which enable to come out with extraction of important information which enables to propose effective method for diagnosis of various turn to turn and phase to ground faults.

\section{INDUCTION MOTOR SIMULATION}

According to $112^{\text {th }}$ standard of IEEE, the methods of testing and operating parameters at lower frequencies upto $400 \mathrm{~Hz}$, the winding of rotor with neutral and stator winding with neutral were divided by the airgap length. The frequencies of rotor quantities and stator quantities also differ with respect to each other. 


\section{A Discrete Wavelet transform based Protection Scheme for Three Phase Induction Motor}

The required important parameters like efficiency, pf, line current, supply frequency can be evaluated with the help of proposed transfer function under lower frequencies by virtue of available quantities like shaft torque, hp of motor, output power.

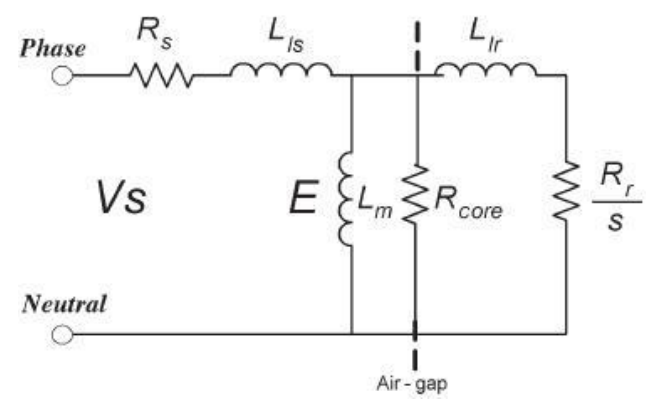

Fig 2. Low-frequency per phase circuit according to $112^{\text {th }}$ IEEE standard.

The responses of 3 phase induction motor under high frequencies were investigated. There are two motor models under high frequencies namely lumped parameter model and distributed parameter model. The surge voltage distributed along the winding obtained with the help of distributed parameter model[7].

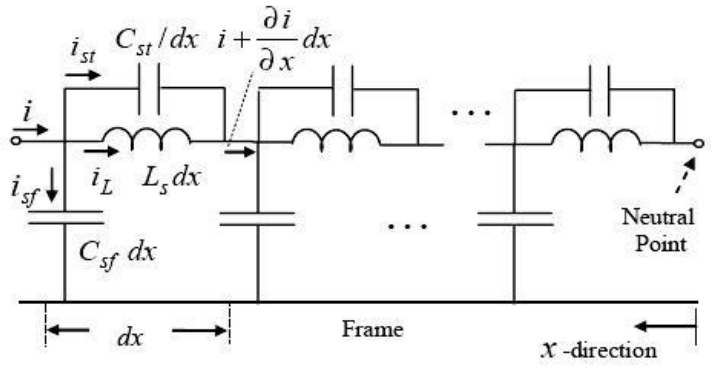

Fig 3. Stator winding distributed model under higher frequencies.

The steady state behaviour of the motor under lower frequencies obtained with the help of T-equivalent circuit as shown in Fig 4

$\mathrm{C}_{\mathrm{sf}-\text { eff }}, \mathrm{C}_{\mathrm{sfo}}, \mathrm{C}_{\mathrm{sw}}$ are added to Equivalent T model of induction motor for obtaining resonant, anti resonant frequency models in Fig.4 to the characteristics of motor under medium, high frequencies. $C_{\mathrm{sf}}$ stator-to frame capacitance. $\mathrm{C}_{\text {sf-eff }}$ is the stator-to-frame effective capacitance of the first slot per phase. $C_{\text {sfo }}$ is the stator-to-frame capacitance star connection with neutral. $C_{\mathrm{sw}}$ capacitance is the stator interturn per phase capacitance.

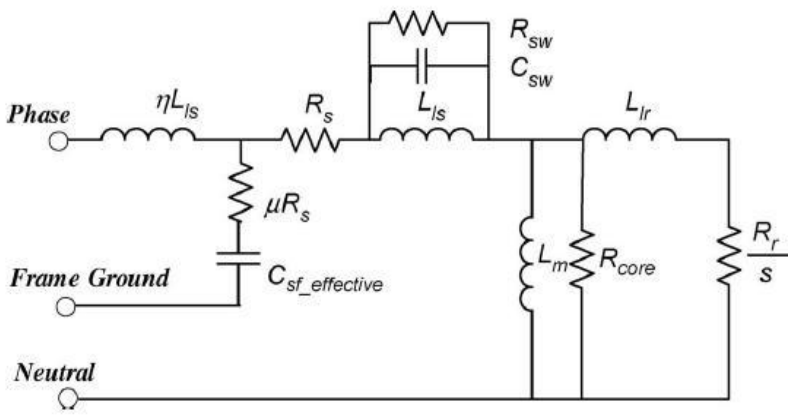

Fig 4. Universal per phase induction motor proposed model.

The mathematical model[10] of the induction motor used for simulation is shown below in Fig 5. The proposed universal model can be used under different frequencies. A three-phase, 5HP, 460V Induction Motor with four poles, 36 no. of slots, 6 no. of coils per phase and 30 no. of turns per coil is considered. Each stator winding coil represented by a pimodel (distributed) given in below figure. 5

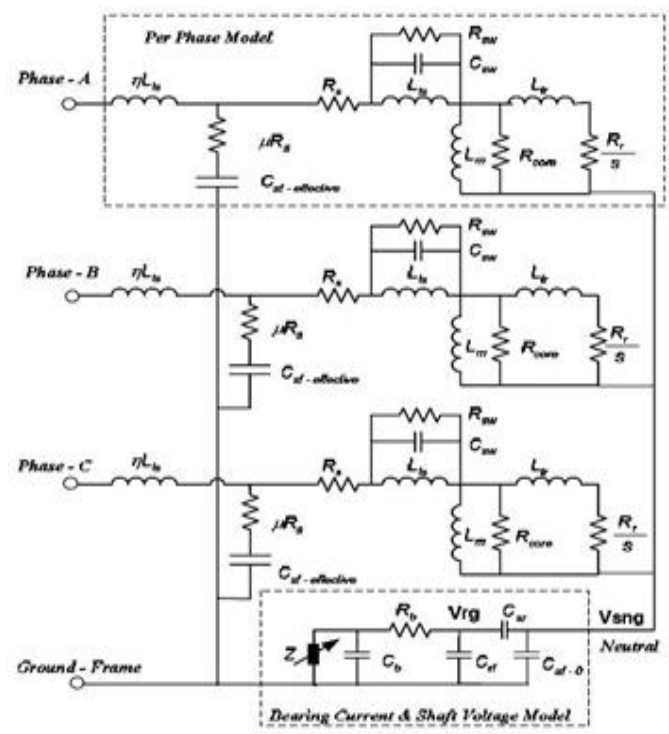

Fig 5. 3 ph universal induction motor model which includes bearing current-shaft voltage model to stator winding to neutral.

Method of identifying proposed model Parameters

i) Resistance of stator $R_{s}$ :

Its value is cold or hot resistance specified by the manufacturer. Ohmic losses at different harmonic frequencies, carrier's frequency, reflection wave ring frequency all are included with damping resistance $R_{\mathrm{sw}}$. ii)Iron Loss Resistance $R_{\text {core: }}$ :

In general its value is $R_{\text {core }}=0.6958 \mathrm{ohm}$ for 6.3kHP At greater values of hp it plays significant role.

iii) Resistance of rotor $R_{r}$, Inductance of rotor $L_{l r}$, Slip s:

According to the T-model including skin effects of deep rotor bars.

iv) Magnetisation Inductance $\mathrm{L}_{\mathrm{m}}$ :

It's value is predominantly lower and can be omitted.

v) Leakage Inductance of stator $\mathrm{L}_{\mathrm{ls}}$ :

It is reduced at abnormal frequencies. $\eta \mathrm{Lls}$ symbolizes partial part at higher frequency antiresonant condition ( 3 to $10 \mathrm{MHz}$ ). So, $\eta \mathrm{Lls}=2 \mathrm{Lls}$. The maker provides the specifications.

vi) $\mathrm{C}_{\text {sf-total }}$ per phase:

The frequencies above the $1^{\text {st }}$ resonant frequency $\left(f_{r 1}\right)$, the capacitance $C_{\text {sf-slot }}$ has vital role in specifying the DM,CM of motor at high frequency, $C_{\text {sf-total }}$ has a role in equalising the $\mathrm{CM}$ transfer function at lower frequencies. The stator slots contain conductors of rectangular cross section with stator length of $L_{\text {stack }}$, slot width $w_{\text {slot }}$, slot depth $d_{\text {slot }}$. 
an induction motor with slots in stator of $N_{\text {slot }}$ and a two layer winding, the total capacitance of winding of stator to its frame is described as

$$
C_{\text {sf-total }}=0.5\left(N_{\text {slot }} C_{\text {sf-slot }}\right)
$$

vii) CM Capacitance of Stator to frame $\mathrm{C}_{\mathrm{sf}-0}$ :

$\mathrm{C}_{\mathrm{sf}-0}$ is the capacitance-to ground present in the lumped neutral star connected. It's given as below

$$
\mathrm{C}_{\mathrm{sf}-0}=\mathrm{C}_{\mathrm{sf}-\text { total }}-3 \mathrm{C}_{\mathrm{sf}-\mathrm{eff}}
$$

viii) Turn-to-Turn Capacitance of stator winding $\mathrm{C}_{\mathrm{sw}}$ :

there are different methods to determine this capacitance. The method where $2^{\text {nd }}$ resonant frequency is nearly double or below that of $1^{\text {st }}$ resonant frequency. it is given as,

$$
\mathrm{C}_{\mathrm{sw}}=\left(\mathrm{f}_{\mathrm{r} 2} / \mathrm{f}_{\mathrm{r} 1}\right)^{2} \mathrm{C}_{\mathrm{sf}-\mathrm{eff}}
$$

ix) Inter turn Damping Resistance of stator winding $\mathrm{R}_{\mathrm{sw}}$ :

It includes the skin,proximity effects and iron losses at higher frequencies.It is obtained that iron loss resistance $R_{\text {core }}$ didn't have much effect on damping. Skin, proximity effect factors at the resonance frequency multiplied by $R_{\mathrm{dc}}$ gives a value which can be converted to parallel $R_{\mathrm{sw}}$.

$\mathrm{x})$ Frame-to-Ground initial Damping Resistance of stator $\mu R_{s}$ :

It is the fractional part of ac resistance of stator resistance $R_{s}$ due to $\eta L_{\mathrm{ls}}$. $\mu R_{s}$ value is directly proportional to the $R_{s}$, a multiplication factor of 10 to 20 for skin, proximity effects. It effects maximum CM current, oscillation damping.

Table for parameters of Induction motor

\begin{tabular}{|c|c|}
\hline PARAMETERS & RATINGS OF 5HP IM \\
\hline Type & Star \\
\hline No.of parallel paths & One \\
\hline Length of stack in milli meters & 114.3 \\
\hline Ns & 36 \\
\hline Width of stator slots in milli meters & 6.96 \\
\hline Ds in milli meters & 18.67 \\
\hline $\operatorname{Rs}(\Omega)$ & 1.410 \\
\hline $\operatorname{Rr}(\Omega)$ & 1.280 \\
\hline L1s(mH) & 11.350 \\
\hline L1r(mH) & 15.040 \\
\hline Lm(mH) $(m)$ & 319 \\
\hline Rcore $(\Omega)$ & 2568 \\
\hline Csf-slot(nF) & 0.213 \\
\hline Csf-effective(nF) & 0.213 \\
\hline Csf-total(nF) & 3.834 \\
\hline Csf-o(nF) & 3.195 \\
\hline Csw $(\mathrm{nF})$ & 0.852 \\
\hline & \\
\hline & \\
\hline
\end{tabular}

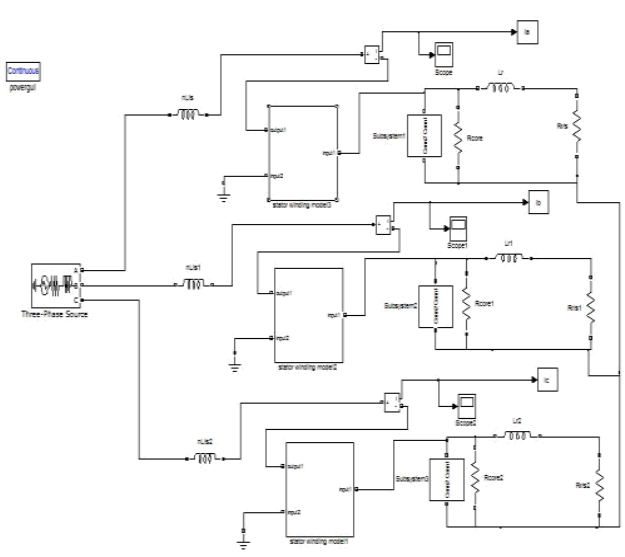

Fig 6.Simulation model of a 3 phase induction motor.

Retrieval Number C6890098319/2019@BEIESP i) Case study:

a) Inter turn fault:

Faults that occur in stator winding due to failure of insulation due to abnormalities like thermal, mechanical and dielectric stress. It results in inter turn fault also phase to ground fault[4]. An Inter turn fault is incorporated in induction motor model by shorting appropriate number of turns. In this paper the fault is carried out by shorting 4 turns in each coil in each phase individually by placing a circuit breaker across the turns.

And the fault is created at 3rd cycle, the simulation is carried out at zero switching instant. And the detection is done with d1 coefficients by applying wavelets and classification with the energy of $\mathrm{d} 1$ coefficients.

b) L-G fault:

Another fault in stator winding is line to ground fault. This fault is also due to insulation failure. In this model fault is incorporated by connecting the last 4 turns in a coil to ground through a breaker. Fault is observed in each coil of each phase.

The faulty currents are analyzed by applying wavelets and classified by calculating the energies of d1coefficients.

\section{WAVELET BASED INDUCTION MOTOR PROTECTION}

The Multi resolution analysis uses a moving window of variable length to get phenomenal results in analyzing fault conditions. In comparison with Fourier Transform, wavelet based MRA provides better resolution due to moving window analysis, which extracts important information from transient signals. By using MRA applying multi level decompositions, detailed and approximation coefficients obtained to realize detection of various kinds of faults and also to classify them through algorithms.

\section{FAULT DETECTION AND CLASSIFICATION}

Here $\mathrm{db} 4$ used as mother wavelet. The signals were decomposed at level 1 . The detail coefficients obtained here used for fault detection.

The detailed coefficients of phase currents used to obtain energy values. When the obtained 3 phases energy values were more than threshold, then the motor is exposed to a fault. The type of fault can be determined by calculating the energy values of current signals under fault and defining a pre-defined range of energy value for various faults.

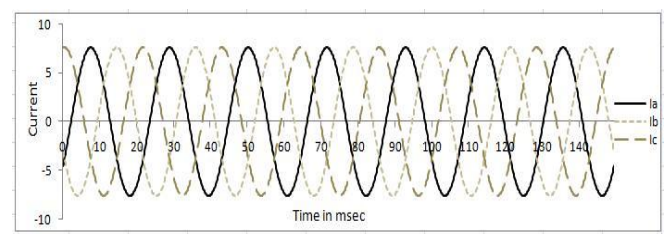

Published By:

Blue Eyes Intelligence Engineering 6368 \& Sciences Publication 


\section{A Discrete Wavelet transform based Protection Scheme for Three Phase Induction Motor}

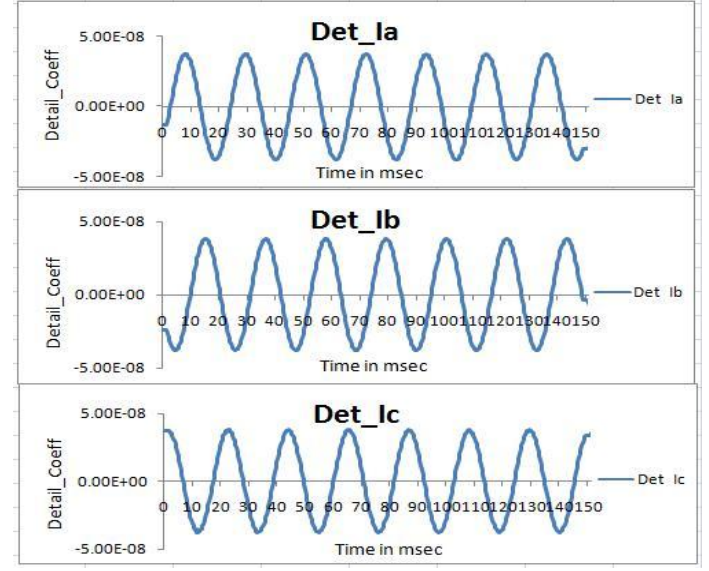

Fig 7. Three phase line currents and Detail coefficients for healthy
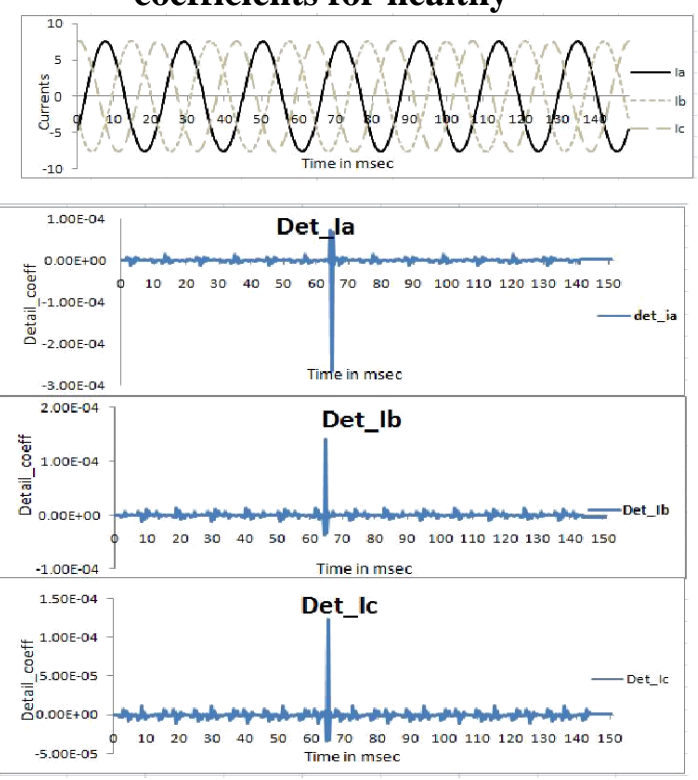

Fig 8.Three Phase line currents and Detail Coefficients for Interturn Fault

1. FAULT DIAGNOSIS:

1(a) DIAGNOSIS OF SHORT CIRCUIT FAULT:

Threshold setting for Phase to Ground Fault in Phase A,B,C \& Healthy case

\begin{tabular}{|c|c|c|c|c|}
\hline FAULT IN & Ia & Ib & Ic & THRESHOLD \\
\hline Phase A & $7.49 \mathrm{E}-08$ & $2.14 \mathrm{E}-08$ & $1.69 \mathrm{E}-08$ & $3.24 \mathrm{E}-08$ \\
\hline Phase B & $9.84 \mathrm{E}-08$ & $4.49 \mathrm{E}-07$ & $1.28 \mathrm{E}-08$ & $3.24 \mathrm{E}-08$ \\
\hline Phase C & $5.35 \mathrm{E}-09$ & $4.15 \mathrm{E}-09$ & $1.87 \mathrm{E}-07$ & $3.24 \mathrm{E}-08$ \\
\hline Healthy & $3.24 \mathrm{E}-13$ & $3.24 \mathrm{E}-13$ & $3.24 \mathrm{E}-13$ & $3.24 \mathrm{E}-08$ \\
\hline
\end{tabular}

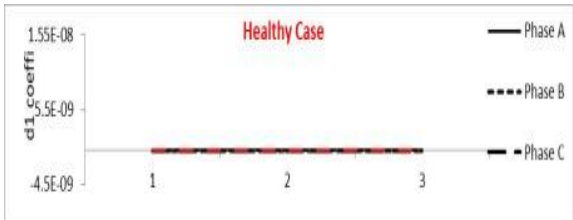

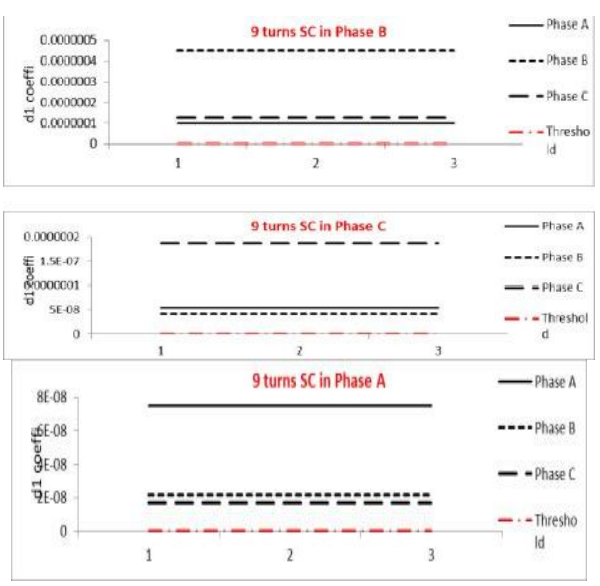

Fig 9 Threshold setting for Phase to Ground Fault in Phase A,B,C \& Healthy case

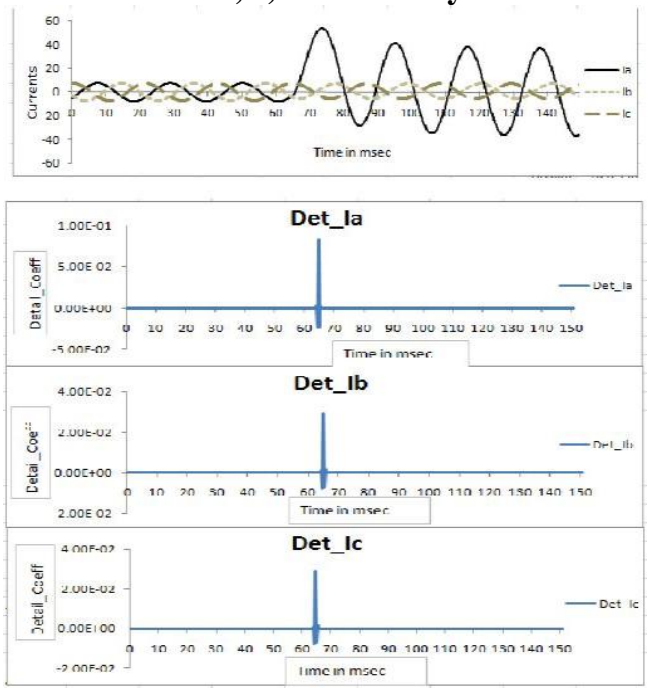

Fig 10.Three phase line currents and Detail Coefficients for Ground Fault

1(b) DIAGNOSIS OF L-G FAULT:

Threshold setting for Phase to Ground fault in Phases A,B,C respectively

\begin{tabular}{|c|c|c|c|c|}
\hline $\begin{array}{c}\text { FAULT } \\
\text { IN }\end{array}$ & $\begin{array}{c}\text { ENERGY } \\
\text { OF IA }\end{array}$ & $\begin{array}{c}\text { ENERGY } \\
\text { OF IB }\end{array}$ & $\begin{array}{c}\text { ENERGY OF } \\
\text { IC }\end{array}$ & $\begin{array}{c}\text { THRESHO } \\
\text { LD }\end{array}$ \\
\hline COIL 1 & 1249.544218 & 78356.6835 & 1581.33273 & 1122.841 \\
\hline COIL 2 & 1252.215199 & 92128.6787 & 1579.49152 & 1122.841 \\
\hline COIL 3 & 1254.711794 & 110027.261 & 1577.79478 & 1122.841 \\
\hline COIL 4 & 1257.066422 & 133893.762 & 1576.20847 & 1122.841 \\
\hline COIL 5 & 1259.29 & 166727.510 & 1574.72608 & 1122.841 \\
\hline COIL 6 & 1261.424775 & 213673.824 & 1573.30580 & 1122.841 \\
\hline
\end{tabular}

\begin{tabular}{|c|c|c|c|c|}
\hline $\begin{array}{c}\text { FAULT } \\
\text { IN }\end{array}$ & $\begin{array}{c}\text { ENERGY } \\
\text { OF IA }\end{array}$ & $\begin{array}{c}\text { ENERGY } \\
\text { OF IB }\end{array}$ & $\begin{array}{c}\text { ENERGY OF } \\
\text { IC }\end{array}$ & $\begin{array}{c}\text { THRESHO } \\
\text { LD }\end{array}$ \\
\hline COIL 1 & $7.393+04$ & $1.14 \mathrm{E}+03$ & $1.71 \mathrm{E}+03$ & 1122.841 \\
\hline COIL 2 & $8.79 \mathrm{E}+04$ & $1.14 \mathrm{E}+03$ & $1.72 \mathrm{E}+03$ & 1122.841 \\
\hline COIL 3 & $1.06 \mathrm{E}+05$ & $1.13 \mathrm{E}+03$ & $1.72 \mathrm{E}+03$ & 1122.841 \\
\hline COIL 4 & $1.31 \mathrm{E}+05$ & $1.13 \mathrm{E}+03$ & $1.73 \mathrm{E}+03$ & 1122.841 \\
\hline COIL 5 & $1.64 \mathrm{E}+05$ & $1.13 \mathrm{E}+03$ & $1.73 \mathrm{E}+03$ & 1122.841 \\
\hline COIL 6 & $2.12 \mathrm{E}+05$ & $1.12 \mathrm{E}+03$ & $1.73 \mathrm{E}+03$ & 1122.841 \\
\hline
\end{tabular}




\begin{tabular}{|c|c|c|c|c|}
\hline $\begin{array}{c}\text { FAULT } \\
\text { IN }\end{array}$ & $\begin{array}{c}\text { ENERGY } \\
\text { OF IA }\end{array}$ & $\begin{array}{c}\text { ENERGY } \\
\text { OF IB }\end{array}$ & $\begin{array}{c}\text { ENERGY } \\
\text { OF IC }\end{array}$ & $\begin{array}{c}\text { THRESH } \\
\text { OLD }\end{array}$ \\
\hline COIL 1 & $\begin{array}{c}1392.854 \\
2\end{array}$ & 1625.74418 & 19021.36624 & 1122.841 \\
\hline COIL 2 & 1390.032 & 1631.9962 & 21693.47534 & 1122.841 \\
\hline COIL 3 & $\begin{array}{c}1387.401 \\
2\end{array}$ & 1637.87858 & 25064.32479 & 1122.841 \\
\hline COIL 4 & 1384.94 & 1643.41837 & 29403.69016 & 1122.841 \\
\hline COIL 5 & $\begin{array}{c}1382.633 \\
6\end{array}$ & 1648.67134 & 35126.06208 & 1122.841 \\
\hline COIL 6 & $\begin{array}{c}1380.456 \\
7\end{array}$ & 1653.61531 & 42894.18332 & 1122.841 \\
\hline
\end{tabular}

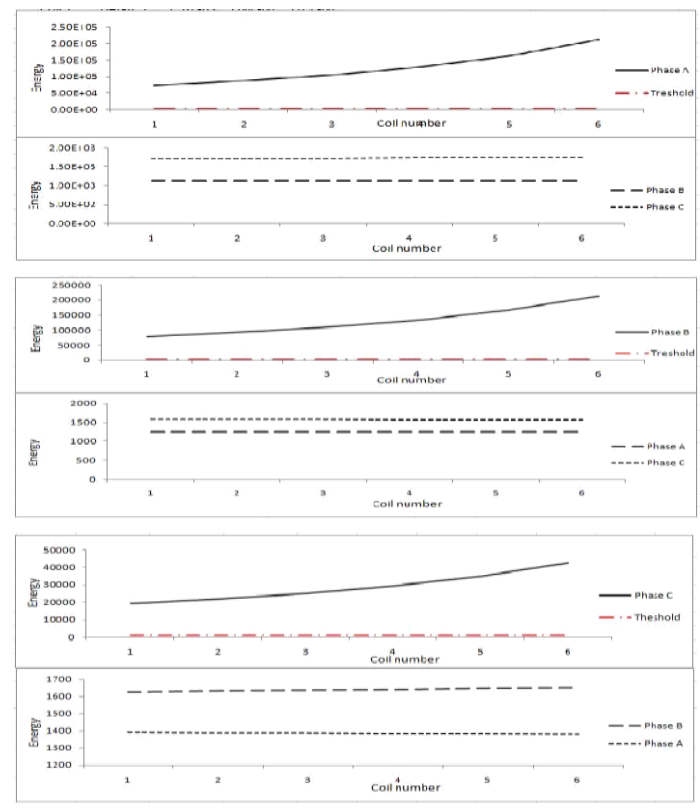

\section{Fig 11.Threshold setting for $L-G$ fault in $A, B, C$ phases respectively}

Depending on energy values of the current signals, the faults are diagnosed and classified.

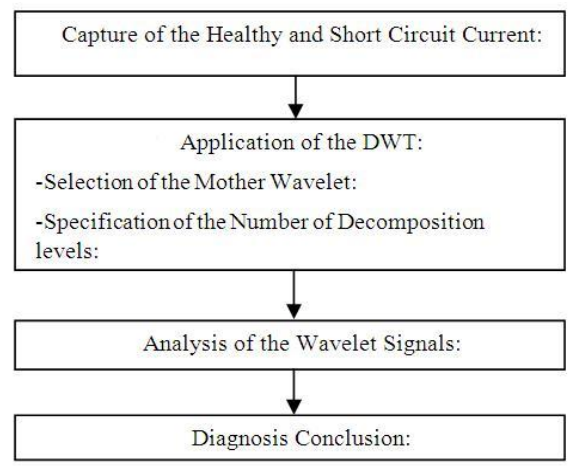

Fig 12.Flow Chart

\section{CONCULSION}

The Proposed WT based diagnosis of faults on induction motor is reliable and accurate. Here the first level detailed coefficients (d1) of db4 extracted from original current signals are used for fault detection. When the Fault Index exceeds the threshold value, the machine is said to expose to fault. The energy values of original current signals are calculated which is used for the fault classification. First threshold is taken as $3.24 \mathrm{E}-08$ to diagnose the phase to ground faults all phases. Phase current signals having their energies of $\mathrm{d} 1$ coefficients more than threshold will be effected phase. Second threshold is considered for diagnosis of L-G fault. Threshold value is 1122.84 . Obtained energy of phase current more thanthreshold in faulty phase. The energy of the signal increases from first coil to sixth coil.

\section{ACKNOWLEDGMENT}

The Authors express their sincere thanks to EEE Department \& Management of PSCMR CET, KL University for their support in completion of this work.

\section{REFERENCES}

1. J. Cusido, L. Romeral, J. A. Ortega, J. A. Rosero, and A Garcia Espinosa, "Fault detection in induction machines using power spectral density in wavelet decomposition,"IEEE Trans.Ind. Electron., Vol. 55, No. 2, pp. 633-643, Feb. 2008.

2. R. Polikar, The Wavelet Tutorial. [Online]. Available: http://engineering.rowan.edu/ polikar/WAVELETS/WTutorial.html.

3. C. S. Burrus, R. A. Gopinath, and H. Guo, Introduction to Wavelets and Wavelet Transforms. A Primer. Englewood Cliffs, NJ: PrenticeHall1998.

4. R.Dash, B.Subudhi, S.Das and A.Mishra, "Neural network and wavelet techniques for detection of interturn short circuit fault in stator winding of an induction motor," international journal on power system optimization and control,vol.1, no.2, pp. 57-63, jul-dec. 2009.

5. A. Boglietti and E. Carpaneto, "Induction motor high Frequency model," in Conf. Rec. IEEE IAS Annu.Meeting, Phoenix, AR,Oct. 1999, pp. 1551-1558.

6. A. F. Moreira, T. A. Lipo, G. Venkataramanan, and S.Bernet, "High frequency modeling for cable and induction motor overvoltage studies in long cable drives," IEEE Trans. Ind. Appl., vol. 38, no. 5, pp. 1297-1306, Sep./Oct. 2002.

7. D. Schlegel, "Development of a high frequency induction motor model for reflected wave simulations," in Masters Design Project. Milwaukee,WI: Milwaukee School Of Engineering, Apr. 1999.

8. T. W. S. Chow and S. Hai, "Induction machine fault diagnostic analysis with wavelet technique," IEEE Trans.Ind. Electron., vol.51, no. 3, pp.558-565, Jun. 2004.

9. W. Thomson and M. Fenger, "Current signature analysis to Detect induction motor faults," IEEE Ind. Appl. Mag., vol. 7, no.4, pp. 2634,Jul./Aug. 2001.

10. Arkan, D. Kostic-Perovic, P.J. Unsworth "Modelling and ,Simulation of induction motors with inter-turn faults for diagnosis", Electric PowerSystems Research, vol. 75, pp. 57-66, 2005.

11. Vellanki Mehar Jyothi, T. Vijay Muni, S V N L Lalitha, "An Optimal Energy Management System for PV/Battery Standalone System," International Journal of Electrical and Computer Engineering, vol. 6, pp. 2538, 2016

12. T. Vijay Muni, D. Priyanka, S V N L Lalitha, "Fast Acting MPPT Algorithm for Soft Switching Interleaved Boost Converter for Solar Photovoltaic System", Journal of Advanced Research in Dynamical \& Control Systems, Vol. 10, 09-Special Issue, 2018.

13. T Vijay Muni, SVNL Lalitha, B Krishna Suma, B Venkateswaramma, "A new approach to achieve a fast acting MPPT technique for solar photovoltaic system under fast varying solar radiation", International Journal of Engineering \& Technology, Volume7, Issue 2.20, pp-131-135.

14. T Vijay Muni, S V N L Lalitha, "Power Management Strategy in Solar PV System with Battery Protection Scheme”, International Journal of Innovative Technology and Exploring Engineering, Volume 8, Issue 6, pp-960-964.

15. Muni, T.V.; Kishore, K.V. Experimental Setup of Solar-Wind Hybrid Power System Interface to Grid System. Int. J. Modern Trends Sci. Technol. 2016, 2, 1-6.

16. T Vijay Muni, S V N L Lalitha, "Fast Acting MPPT Controller for Solar PV with Energy Management for DC Microgrid”, International Journal of Engineering and Advanced Technology (IJEAT), Volume 8, Issue 5, pp-1539-1544.

17. D. Ravi Kishore, and T. Vijay Muni, "Efficient energy management control strategy by model predictive control for standalone dc micro grids", AIP Conference Proceedings 1992, 030012 (2018); doi: $10.1063 / 1.5047963$

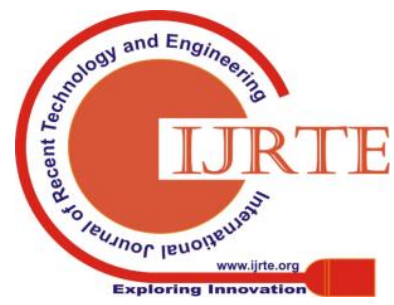

